\title{
Comparison of Plegisol and Modified ST Thomas Hospital Cardioplegic Solution in the Development of Ventricular Fibrillation after Declamping of the Aorta
}

\author{
Mustafa Aldemir $^{1 *}$, Celalettin Karatepe ${ }^{2}$, Elif Doğan Bakı ${ }^{3}$, Görkem Çarşanba ${ }^{1}$, \\ Evren Tecer ${ }^{1}$ \\ ${ }^{1}$ Department of Cardiovascular Surgery, Kocatepe University, Afyonkarahisar, Turkey \\ ${ }^{2}$ Department of Cardiovascular Surgery, Mustafa Kemal University, Antakya, Turkey \\ ${ }^{3}$ Department of Anaesthesiology, Kocatepe University, Afyonkarahisar, Turkey \\ Email: draldemir@yahoo.com
}

Received 22 July 2014; revised 22 August 2014; accepted 22 September 2014

Copyright (C) 2014 by authors and Scientific Research Publishing Inc.

This work is licensed under the Creative Commons Attribution International License (CC BY).

http://creativecommons.org/licenses/by/4.0/

\section{(c) (i) Open Access}

\begin{abstract}
Ventricular fibrillation seen just after declamping of the aorta is an undesirable condition causing myocardial injury. To return to normal rhythm, often internal shocks are applied. But defibrillation itself can also contribute to myocardial injury. So prevention of fibrillation is more important than treatment. 236 patients undergoing coronary artery by-pass surgery were included in this retrospective clinical study. 144 of those patients were operated using modified St. Thomas' Hospital cardioplegic solution, for stopping the heart. In the other 92 patients, plegisol cardioplegic solution was used. We compared the two groups for the development of ventricular fibrilation after declamping of the aorta. In the modified St. Thomas' Hospital group, ventricular fibrillation after declamping of the aorta was seen less frequently, this being statistically significant (22.2\% vs. $52.2 \%, p=0.026$ ). This study shows that the modified St.Thomas' Hospital cardioplegic solution is preferred for avoiding ventricular fibrillation occuring just after declamping of the aorta.
\end{abstract}

\section{Keywords}

Coronary Artery By-Pass Surgery, Cardioplegic Solutions, Ventricular Fibrillation

\footnotetext{
"Corresponding author.
}

How to cite this paper: Aldemir, M., Karatepe, C., Bakı, E.D., Çarşanba, G. and Tecer, E. (2014) Comparison of Plegisol and Modified ST Thomas Hospital Cardioplegic Solution in the Development of Ventricular Fibrillation after Declamping of the Aorta. World Journal of Cardiovascular Surgery, 4, 159-166. http://dx.doi.org/10.4236/wjcs.2014.410023 


\section{Introduction}

In open heart surgery, ventricular fibrillation appearing just after declamping of the aorta is a common, severe energy spending situation. That is why the heart must be defibrillated immediately. But defibrillation is not so harmless and may itself also be a cause of myocardial injury. Dahl and associates studied cardiac damage by measuring creatine phosphokinase isoenzymes, technetium pyrophosphate imaging or histopathologic methods [1]. Prevention of ventricular fibrillation is more important than its treatment for avoiding some adverse outcomes.

Cardioplegic solutions used to stop the heart during distal anastomosis, for drying of the operative field, have been further improved to produce better outcomes. Two of the more common types of cardioplegic solutions formulated with different concentrations of electrolytes and antiarrythmic agents have been used in cardiac surgery. In this study, we aimed to investigate whether there is a difference between two cardioplegic solutions, Plegisol and modified St Thomas' Hospital, in the frequency of ventricular fibrillation occurence after declamping of the aorta. The composition of the solutions is given in Table 1.

\section{Methods}

\subsection{Study Design}

After approval by the local ethics committee of the Afyon Kocatepe University Faculty of Medicine, this retrospective clinical study was performed on a total of 236 patients who underwent isolated coronary artery bypass grafting (CABG) surgery at our institution, Kocatepe University, Departmant of Cardiovascular Surgery, Afyonkarahisar, Turkey, between January 2009 and May 2013. Modified St Thomas’ Hospital cardioplegic solution has been in use since 2011. Before 2011, plegisol cardioplegic solution was used in our clinic. After carefully screening our hospital's computerized database and patient files, 217 patients were found to have underwent CABG using plegisol between 2009 and 2011. We selected 92 patients (Group P, n = 92) meeting our study criteria. From patients who underwent CABG between 2011 and 2013, we carefully screened 253 from the same database and patient files and selected 144 patients (Group S, $n=144$ ) who underwent CABG using St Thomas' Hospital cardioplegic solution. We selected all the patients in each group as those having cardioplegia via only an antegrade route. Myocardial protection in total consisted of administration of one of these solutions via the aortic root (antegrade), along with topical slushed ice and systemic hypothermia $\left(30^{\circ} \mathrm{C}\right)$. All the patients had coronary artery disease with a varying degree of stenosis of the left anterior descending coronary artery. Patients having left main or left main equivalent coronary artery disease were also included in the study. To eliminate effects of grafts on the results, we selected all patients in which the left internal mammarian artery and saphenous vein grafts had been used.

The exclusion criteria were previous dysrythmias, need for any additional procedure such as valve replacement or aortic surgery, re-operation, beating heart surgery, emergency operation, left ventricular dysfunction (EF $<30 \%$ ), renal dysfunction (preoperative serum creatinin level $>1.5 \mathrm{mg} / \mathrm{dL}$ ) and chronic obstructive pulmonary disease.

\subsection{Data Collection and Definitions}

The specific pre-operative data obtained for each patient are shown in Table 2: age and gender, diabetes (fasting blood glucose levels $>140 \mathrm{mg} / \mathrm{dL}$ and the use of oral anti-diabetic medications or insulin dependency), smoking history, hypertension (systolic blood pressure of more than $160 \mathrm{mmHg}$ or a diastolic blood pressure of more than $100 \mathrm{mmHg}$ ), prior percutaneous transluminal coronary angioplasty, preoperative ejection fraction during catheterization, preoperative use of beta blockers, calcium channel blockers or digitalis, previous myocardial infarction (MI), and presence of left main coronary artery disease. All medications such as calcium channel blockers, beta blockers and digitalis were continued until the night before surgery. Nitrates were continued even on the morning of surgery. Antiplatelet drugs were stopped a week prior to the surgery.

The intraoperative variables before declamping for each group are shown in Table 3: Number of grafts per operation, cardiopulmonary bypass time and aortic cross-clamp time, temperature before declamping, serum chemistry determinations just before declamping (potassium, magnesium, calcium), arterial blood gases ( $\mathrm{pH}$, $\mathrm{pCO}_{2}, \mathrm{pO}_{2}$ ) and hemoglobin levels just before declamping.

Need for inotropic drug or intraaortic balloon pump support for weaning from CPB, incidence of ventricular 
Table 1. Composition of cardioplegic solution.

\begin{tabular}{ccc}
\hline Component & $\mathrm{m}-\mathrm{STH}$ & Plegisol \\
\hline $\mathrm{K}^{+}(\mathrm{mmol} / \mathrm{L})$ & 26 & 16 \\
$\mathrm{Na}^{+}(\mathrm{mmol} / \mathrm{L})$ & 110 & 120 \\
$\mathrm{Cl}^{-}(\mathrm{mmol} / \mathrm{L})$ & 159 & 160 \\
$\mathrm{Mg}^{2+}(\mathrm{mmol} / \mathrm{L})$ & 32 & 32 \\
$\mathrm{HCO}_{3}^{-}(\mathrm{mmol} / \mathrm{L})$ & 10 & 10 \\
$\mathrm{Ca}^{2+}(\mathrm{mmol} / \mathrm{L})$ & 2.4 & 2.4 \\
Mannitol & 30 & - \\
Osmolarity $^{\mathrm{a}}$ & 320 & 324 \\
$\mathrm{pH}\left(24^{\circ} \mathrm{C}\right)$ & 8.04 & 7.8 \\
\hline
\end{tabular}

${ }^{\mathrm{a} O s m o l a r i t y, ~ m o s m o l / L, ~ a s ~ d e t e r m i n e d ~ b y ~ f r e e z i n g-p o i n t ~ d e p r e s s i o n . ~ m-S T H: ~ m o d i f i e d ~ S t . T h o m a s . ~}$

Table 2. Preoperative patient data.

\begin{tabular}{cccc}
\hline & Group S (n=144) & Group P (n=92) & “p” value \\
\hline Male & $96(66.7 \%)$ & $36(39.1 \%)$ & 0.04 \\
Age (yr) & $64.33 \pm 10.290$ & $68.61 \pm 6.49$ & 0.13 \\
DM & $56(38.9 \%)$ & $24(26.1 \%)$ & 0.21 \\
Smoking & $80(55.6 \%)$ & $44(47.8 \%)$ & 0.57 \\
Hypertension & $104(72.2 \%)$ & $76(82.6 \%)$ & 0.36 \\
PTCA & $20(13.9 \%)$ & $24(26.1 \%)$ & 0.25 \\
EF (\%) & $48.83 \pm 13.903$ & $48.22 \pm 10.996$ & 0.8 \\
Beta blocker & $92(63.9 \%)$ & $64(69.6 \%)$ & 0.66 \\
Ca channel blocker & $32(22.2 \%)$ & $40(43.5 \%)$ & 0.09 \\
Digitalis & $8(5.6 \%)$ & $16(17.4 \%)$ & 0.15 \\
Previous MI & $40(27.8 \%)$ & $20(21.7 \%)$ & 0.61 \\
LMCA disease & $4(2.8 \%)$ & $0(0 \%)$ & 0.42 \\
\hline
\end{tabular}

Data expressed as mean \pm SD or n. DM: Diabetes mellitus. PTCA: Percutaneous transluminal coronary angioplasty. EF: Ejection fraction, MI: Myocardial infarction. LMCA: Left main coronary artery. S: St. Thomas' Hospital1 solution. P: Plegisol solution.

Table 3. İntraoperative variables before declamping of the aorta.

\begin{tabular}{|c|c|c|c|}
\hline & Group S $(n=144)$ & Group P $(n=92)$ & “p” value \\
\hline No. of grafts & $3.00 \pm 0.99$ & $2.74 \pm 0.69$ & 0.25 \\
\hline CPB time (minutes) & $97.97 \pm 38.46$ & $94.17 \pm 26.91$ & 0.93 \\
\hline Cross clamp time (minutes) & $54.25 \pm 25.65$ & $54.22 \pm 18.42$ & 0.64 \\
\hline Temperature before declamping $\left({ }^{\circ} \mathrm{C}\right)$ & $33.08 \pm 0.78$ & $33.04 \pm 1.19$ & 0.94 \\
\hline \multicolumn{4}{|l|}{ Serum chemistry } \\
\hline Potassium (mmol/L) & $4.39 \pm 0.53$ & $3.68 \pm 0.63$ & $<0.001$ \\
\hline Calcium $(\mathrm{mmol} / \mathrm{L})$ & $0.96 \pm 0.05$ & $0.95 \pm 0.05$ & 0.57 \\
\hline Magnesium (mmol/L) & $1.75 \pm 0.27$ & $1.73 \pm 0.32$ & 0.8 \\
\hline \multicolumn{4}{|l|}{ Arterial blood gases } \\
\hline $\mathrm{pH}$ & $7.36 \pm 0.05$ & $7.37 \pm 0.06$ & 0.58 \\
\hline $\mathrm{pO}_{2}(\mathrm{mmHg})$ & $253.70 \pm 43.10$ & $294.5 \pm 94.87$ & 0.03 \\
\hline $\mathrm{pCO}_{2}(\mathrm{mmHg})$ & $37.70 \pm 3.72$ & $38.04 \pm 7.56$ & 0.6 \\
\hline Hemoglobin level (g/dL) & $7.49 \pm 0.09$ & $7.17 \pm 0.17$ & 0.7 \\
\hline
\end{tabular}

CPB: Cardiopulmonary by-pass. 
fibrillation in the time period between declamping of the aorta and weaning from cardiopulmonary by-pass, and number of applied defibrillations for returning to normal rhythm are summarized in Table 4.

\subsection{Surgical Procedure}

All patients were given the same anesthesia protocol. They were premedicated with midazolam (dormicum 5 $\mathrm{mg} / 5 \mathrm{ml})(0.05 \mathrm{mg} / \mathrm{kg} \mathrm{IV})$. At the operating table, cannulae were inserted in a peripheral vein, the radial artery, and the right jugular vein. Standard monitoring included pulse oximetry, leads II and V5 of the ECG for heart rate and automated ST-segment trend analysis, continuous measurements of arterial and central venous pressures, nasopharyngeal temperature, and end-tidal capnography. A balanced anesthetic technique included fentanyl (bolus of $1-2 \mathrm{mg} / \mathrm{kg}$ followed by intermittent bolus of $1-2 \mathrm{mg} / \mathrm{kg} \cdot \mathrm{h}$ ), etomidate (bolus of $0.2-0.3$ $\mathrm{mg} / \mathrm{kg}$ ), esmeron (bolus of $1 \mathrm{mg} / \mathrm{kg}$ and intermitant bolus of $0.3 \mathrm{mg} / \mathrm{kg} / \mathrm{h}$ ) and inhaled sevofluorane (2\% - 3\% in the prebypass period and $1 \%-1.5 \%$ in the bypass period). Ventilation was modified for each patient to reach partial arterial oxygen pressure above $150 \mathrm{mmHg}$ and partial arterial carbon dioxide pressure above $45 \mathrm{mmHg}$.

A median sternotomy was performed for all patients. Cardiopulmonary bypass (CPB) was established in a standardized manner with the use of a roller pump and non-pulsatile flow $\left(2.4 \mathrm{~L} / \mathrm{m}^{2} / \mathrm{min}\right)$. A heparinization protocol of $300 \mathrm{U}$ per kilogram was followed to maintain clotting time at longer than 400 seconds. All patients were cooled to $30^{\circ} \mathrm{C}$ when distal anastomosis was being performed, and were warmed to $36^{\circ} \mathrm{C}$ before weaning from CPB. After aortic cross clamping, by mixing with a ratio of one unit of cardioplegia to four units of blood, coldblood cardioplegia (modified St.Thomas' Hospital or Plegisol) was accomplished with antegrade delivery through the aortic root for diastolic arresting of the heart initially and after each distal anastomosis intermittently. A final dose of "hot-shot" cardioplegia was also administered antegradely just before the aorta was unclamped. Protamine was used to reverse the effects of heparinization. If ventricular fibrillation occurred after the aorta was unclamped, it was electrically cardioverted with 10- to 20-joule internal shocks.

\subsection{Cardioplegia}

St.Thomas' Hospital cardioplegic solution was used in group S and plegisol solution in group P. Every $100 \mathrm{ml}$ of solution was prepared in $0.9 \% \mathrm{NaCL}$ (Ecotainer ${ }^{\circledR} 250 \mathrm{ml}, 500 \mathrm{ml}, 1000 \mathrm{ml}$ ) as shown in Table 1 and mixed with ringer's lactate to give $1000 \mathrm{ml}$ of cardioplegic solution. The final solutions, after mixing with blood in a ratio of one unit of cardioplegia to four units of blood, was administered antegradely through the cardioplegic line in the proximal aorta and repeated every 20 min during the time of cross-clamping.

\section{Statistical Analysis}

The values obtained from the groups were compared to evaluate the relationship between the development of ventricular fibrillation and cardioplegic solutions (Plegisol and St. Thomas' Hospital). Statistical analysis was performed with SPSS version 15.0 (SPSS, Inc., Chicago, IL) software. Compliance of variables with a normal distribution was analyzed with visual methods (histogram and probability plots) and analytical methods (the Kolmogorov-Smirnov test). Descriptive analyses are provided as mean and standard deviation. Comparisons between groups were performed with Pearson ki-square test and Mann-Whitney U test. The results were accepted as statistically significant when $\mathrm{p}$ value was $<0.05$.

Table 4. Variables of each group after declamping of the aorta.

\begin{tabular}{cccc}
\hline & Group S (n=144) & Group P (n= 92) & "p” value \\
\hline Inotropic drug usage & $68(47.2 \%)$ & $48(52.2 \%)$ & 0.79 \\
Intraaortic balloon pump usage & $0(0 \%)$ & $4(4.3 \%)$ & 0.39 \\
VF & $32(22.2 \%)$ & $48(52.2 \%)$ & $\mathbf{0 . 0 2 6}$ \\
No. of defibrillations & & 28 & 1.00 \\
1 & 20 & 20 & 1.00 \\
\hline
\end{tabular}

VF: Ventricular fibrillation. 


\section{Results}

A total of 236 patients were studied, 144 in the modified St Thomas' Hospital group (group S) and 92 in the plegisol group (group P). A slightly higher percent of patients in Group S (66.7\%) were male compared to Group P (39.1\%), and this difference was statistically significant $(p=0.04)$. Except for the difference of sex, patient characteristics were similar in the two study groups (Table 2).

In both groups, CPB time, cross-clamp time, number of by-passed grafts and body temperature just before declamping were similar, and these variables were not statistically different in each group. $\mathrm{P}$ values are shown in Table 3.

The results of serum chemistry studies just before declamping of the aorta showed that the difference in calcium and magnesium concentrations between the two groups were not statistically significant ( $p=0.57$ for calcium and $\mathrm{p}=0.80$ for magnesium). However, the serum potassium concentration in group $\mathrm{S}(4.39 \pm 0.53)$ was higher than in group $\mathrm{P}(3.68 \pm 0.63)$ and this difference was statistically singificant $(\mathrm{p}<0.001)$.

When we looked at arterial blood gas analysis, we found that $\mathrm{pH}$ and $\mathrm{pCO}_{2}$ were similar in both groups. But $\mathrm{pO}_{2}$ values in group S $(253.70 \pm 43.10)$ were lower than in group $\mathrm{P}(294.5 \pm 94.87)$ and the difference between the two groups was statistically significant $(\mathrm{p}=0.031)$. Mean hemoglobin levels just before declamping of the aorta in group $\mathrm{S}$ were $7.49 \pm 0.09$ and $7.17 \pm 0.17$ in group $\mathrm{P}$, and this difference was not statistically significant $(\mathrm{p}=0.70)$.

In group S, 68 patients (47.2\%) and in group P 48 patients (52.2\%) needed inotropic drug support at the time from declamping of the aorta until transport to the intensive care unit. The difference between the two groups was not statistically significant $(\mathrm{p}=0.79)$. Intraaortic balloon counterpulsation usage in the two groups were similar. In group $\mathrm{S}$, none of the patients needed IABP, in group $\mathrm{P}$, four patients needed IABP, but this was not statistically significant $(\mathrm{p}=0.39)$. The development of ventricular fibrillation after declamping of the aorta until weaning from cardiopulmonary by-pass was seen in 32 patients of group S (22.2\%) but was seen in 48 patients in group P (52.2\%) and this difference between the two groups was statistically significant $(p=0.026)$. When seeing ventricular fibrillation, internal shock numbers applied for returning to normal rhythm were similar in both groups.

\section{Discussion}

The heart is commonly vulnerable to ventricular fibrillation at the time just after declamping of the aorta [2]. The mechanism of ventricular fibrillation appearing at that time is not precisely understood. It is well known that many factors contribute, such as electrolyte and acid disturbances or gradients, conduction abnormalities and more importantly inadequate myocardial preservation may play a role [3]. The best method must be developed for protection of the heart from myocardial injury during open heart surgery [4]. Cardioplegic solutions have a key role in this point. Although the delivery method of cardioplegic solutions is important, so is the type of solution.

Modified St.Thomas' Hospital and plegisol are commonly used prepared cardioplegic solutions. In the literature, there are many studies related to their effects on ventricular function [5]. Ventricular function after open heart surgery largely depends on the degree of myocardial ischemia during the operation [6]. Ventricular fibrillation after declamping of the aorta is in close relation with the ischemic period [7]. So the choice of cardioplegic solution is important in this aspect also.

As investigations on myocardial protection techniques have been advanced, additives, temperature and contents of cardioplegic solutions vary. In spite of these evolutions, there is no technique that completely protects myocardial function [8]. Crystalloid cardioplegic solutions are inexpensive and simple to use in this era. They greatly protect the myocardium from destructive changes and are associated with good patient outcomes [9]. Cardioplegic solutions make the heart tolerable for long ischemic and reperfusion events by providing additional buffer, balancing electrolye-osmotic disturbances, and supplying substrates for phosphorylation [10].

In this present study, our data show that modified St.Thomas' Hospital cardioplegic solution is superior to plegisol for preventing ventricular fibrillation just after declamping of the aorta. It has a low sodium ion concentration and contains mannitol as colloid. Low extracellular sodium concentration leads to cardiac arrest by depriving substrate for the fast sodium upstroke of the action potential, supported by a slight elevation of the extracellular potassium concentration [11]. In contrast to plegisol, modified St.Thomas' Hospital solution prevents further myocardial cell swelling by reducing sodium-potassium exchange pump activity during hypother- 
mia [12]. When compared to plegisol, with modified St.Thomas' Hospital solution cellular edema is less likely to be seen because of the reduction of the inward sodium gradient [13]. Mannitol as an additive counteracts colloidal osmotic pressure of intracellular proteins and other components of the cytosol. Less edema is attributed to the hyperosmolar properties of mannitol. Edema can develop only if the rate at which fluid filters into the tissues exceeds the rate at which fluid is removed by myocardial lymphatics [14].

The relation between potassium content of the cardioplegic solutions and the incidence of ventricular fibrillation is noteworthy [15]. In this present study, mean serum potassium level at the time just after declamping of the aorta was higher in the modified St. Thomas' Hospital group than in the plegisol group. The stabilizing effect of potassium on ventricular fibrillation after declamping of the aorta has been much studied previously [15]. Sven M. Almdahl et al. demonstrated that potassium infusion is an effective and convenient first-hand measure to convert post declamping VF on CPB [3]. Marcus L Koller et al., in an experimental model, demonstrated the anti-fibrillatory effect of hyperkalaemia on sustained VF. [16] In our study, all ventricular fibrillation episodes in each group were easily converted by electrical cardioversion, not needing any potassium as an external additive. But potassium amounts in both cardioplegic solutions can be equalized with additional potassium before use. It can be thought that higher serum potassium levels just after declamping of the aorta in Group S was a favored condition for lower ventricular fibrillation incidence.

To prevent ventricular fibrillation just after declamping of the aorta, some additives to cardioplegic solutions were measured in past studies. Sellevold O.F. et al. demonstrated that procaine $(1 \mathrm{mM})$ in cardioplegia stabilizes the post-ischemic rhythm in CABG surgery in humans without any observed adverse effects [17]. Fulii M proposed esmolol addition into cardioplegic solutions as an alternative to hyperkalaemic cardioplegias, and he concluded in his study that blood-based esmolol cardioplegia improved cardioprotective efficacy compared with hyperkalaemic cardioplegia [18].

Certainly, there are many other factors, such as asidosis and hypoxia, that contribute to the development of ventricular fibrillation after declamping of the aorta and to the success of electrical cardioversion [19]. In our study, arterial blood gas analysis just before declamping of the aorta was within normal limits in each group. $\mathrm{PO}_{2}$ values in group $\mathrm{S}$ were lower, being statistically significant, but they were also within normal limits. Indeed, ventricular fibrillation incidence was lower in Group S.

When screening the literature, we found a number of studies on the relation between preoperative $\beta$-blocker usage and the development of postoperative atrial fibrillation. The evidence as to whether atrial arrhythmias are more or less common in patients on preoperative $\beta$-blockers is inconclusive. Srivinasan AK et al. showed that the incidence of atrial fibrillation is higher in patients on preoperative $\beta$-blocker therapy. But they linked this condition to not initiating $\beta$-blocker therapy after the operation, unless clinically indicated. Additionally, their study was retrospective and this was a limitation of their study [20]. On the other hand, Koçoğullari CU et al. showed a decreased incidence of atrial fibrillation with preoperative $\beta$-blocker therapy [21]. Several other studies also showed that initiation of $\beta$-blocker therapy preoperatively reduces the incidence of atrial fibrillation after CABG [22] [23]. As is understood from screening the literature, there has not been any designed study on the relation between preoperative $\beta$-blocker and postoperative ventricular arryhthmias. In our study, the two groups were similar in this aspect. This could also be the subject of another study.

Our study has some limitations. First of all, it was a retrospective study. Although we screened data very carefully, trying to get information on CABG only for those pure blood-cardioplegia solutions without any additives used throughout the cross-clamping period, in actuality, some practices might not have been recorded. Secondly, serum potassium levels just before declamping of the aorta might have significant effects on the results. Nevertheless, this data could be accepted as a favored recommendation of modified St.Thomas' Hospital cardioplegia solution. More prospective studies must be designed to expand the application of modified St Thomas' Hospital cardioplegic solution in the prevention of ventricular fibrillation after declamping of the aorta.

\section{Conclusion}

Our study has shown that in patients who underwent CABG using modified St.Thomas' Hospital cardioplegic solution, the incidence of ventricular fibrillation just after declamping of the aorta was lower than with plegisol cardioplegia.

\section{Acknowledgements}

The authors acknowledge with gratitude the cooperation of people who collected and managed the database of 
our institution.

\section{Conflict of Interest}

All the authors disclose no financial relationship with a biotechnology manufacturer, a pharmaceutical company, or other commercial entity that has an interest in the subject matter or materials discussed in the manuscript.

\section{References}

[1] Dahl, C.F., Ewy, G.A., Warner, E.D. and Thomas, E.D. (1974) Myocardial Necrosis from Direct Current Countershock. Circulation, 50, 956-961. http://dx.doi.org/10.1161/01.CIR.50.5.956

[2] Jynge, P. and Sellevold, O.F. (1987) Cardioplegia: Mechanisms of Protection Revisited. Annales Chirurgiae Et Gynaecologiae, 76, 22-29.

[3] Almdahl, S.M., Damstuen, J., Eide, M., Mølstad, P., Halvorsen, P. and Veel, T. (2013) Potassium-Induced Conversion of Ventricular Fibrillation after Aortic Declamping. Interactive CardioVasc Thoracic Surgery, 16, 143-150. http://dx.doi.org/10.1093/icvts/ivs455

[4] Mehlhorn, U., Davis, K.L., Burke, E.J., Adams, D.L., Laine, G.A. and Allen, S.J. (1995) Impact of Cardiopulmonary Bypass and Cardioplegic Arrest on Myocardial Lymphatic Function. American Journal of Physiology, 268, H178H183.

[5] Chambers, D.J. and Fallouh, H.B. (2010) Cardioplegia and Cardiac Surgery: Pharmacological Arrest and Cardioprotection during Global Ischemia and Reperfusion. Pharmacology \& Therapeutics, 27, 41-52. http://dx.doi.org/10.1016/j.pharmthera.2010.04.001

[6] Tang, X.N. and Yenari, M.A. (2010) Hypothermia as a Cytoprotective Strategy in Ischemic Tissue Injury. Ageing Research Reviews, 9, 61-68. http://dx.doi.org/10.1016/j.arr.2009.10.002

[7] Sarusi, A., Rárosi, F., Szűcs, M., Csík, N., Farkas, A.S., Papp, J.G., et al. (2014) Absolute Beat-to-Beat Variability and Instability Parameters of ECG Intervals: Biomarkers for Predicting Ischaemia-Induced Ventricular Fibrillation. British Journal of Pharmacology, 171, 1772-1782. http://dx.doi.org/10.1111/bph.12579

[8] Krukenkamp, I.B. and Levitsky, S. (1996) Physiological and Cellular Mechanisms of Myocardial Protection. The American Journal of Surgery, 172, 79-84. http://dx.doi.org/10.1016/S0002-9610(96)00075-X

[9] Hendry, P.J., Masters, R.G. and Haspect, A. (1994) Is There a Place for Cold Crystalloid Cardioplegia in the 1990s? Annals of Thoracic Surgery, 58, 1690-1694. http://dx.doi.org/10.1016/0003-4975(94)91662-4

[10] Careaga, G., Salazar, D., Téllez, S., Sánchez, O., Borrayo, G. and Argüero, R. (2001) Clinical Impact of HistidineKetoglutarate-Tryptophan (HTK) Cardioplegic Solution on the Perioperative Period in Open Heart Surgery Patients. Archives of Medical Research, 32, 296-299. http://dx.doi.org/10.1016/S0188-4409(01)00296-X

[11] Gebhard, M.M., Bretschneider, H.J., Gersing, E., Preusse, C.J., Schnabel, Ph.A. and Ulbricht, L.J. (1983) Calcium-Free Cardioplegia-Pro. European Heart Journal, 4, 151-160. http://dx.doi.org/10.1093/eurheartj/4.suppl_H.151

[12] Shaffer, R.F., Baumgarten, C.M. and Damiano Jr., R.J. (1998) Prevention of Cellular Edema Directly Caused by Hypothermic Cardioplegia: Studies in Isolated Human and Rabbit Atrial Myocytes. The Journal of Thoracic and Cardiovascular Surgery, 115, 1189-1195. http://dx.doi.org/10.1016/S0022-5223(98)70420-9

[13] Stinner, B., Krohn, E., Gebhard, M.M. and Bretschneider, H.J. (1989) Intracellular Sodium Activity and Bretschneider's Cardioplegia: Continuous Measurement by Ionselective Microelectrodes at Initial Equilibration. Basic Research in Cardiology, 84, 197-207. http://dx.doi.org/10.1007/BF01907929

[14] Allen, S.J. and Drake, R.E. (1997) Microvascular Fluid Exchange. In: Yaksh, T.L., Ed., Anesthesia: Biological Foundations, Lippincott-Raven Publ., Philadelphia, 1417-1430.

[15] Praeger, P.I., Kay, R.H., Moggio, R., Somberg, E., Pooley, R., Sarabu, M., Sanshala, V., Kubal, K., Kumar, V. and Reed, G.E. (1988) Prevention of Ventricular Fibrillation after Aortic Declamping during Cardiac Surgery. Texas Heart Institute Journal, 15, 98-101.

[16] Koller, M.L., Riccio, M.L. and Gilmour Jr., R.F. (2000) Effects of (K) on Electrical Restitution and Activation Dynamics during Ventricular Fibrillation. The American Journal of Physiology: Heart and Circulatory Physiology, 279, H2665-H2672.

[17] Sellevold, O.F., Berg, E.M. and Levang, O.W. (1995) Procaine Is Effective for Minimizing Postischemic Ventricular Fibrillation in Cardiac Surgery. Anesthesia Analgesia, 81, 932-938.

[18] Fujii, M. and Chambers, D.J. (2013) Cardioprotection with Esmolol Cardioplegia: Efficacy as a Blood-Based Solution. European Journal of Cardio-Thoracic Surgery, 43, 619-627. http://dx.doi.org/10.1093/ejcts/ezs365

[19] Yakaitis, R.W., Thomas, J.D. and Mahaffey, J.E. (1975) Influence of pH and Hypoxia on the Success of Defibrillation. 
Critical Care Medicine, 3, 139-142. http://dx.doi.org/10.1097/00003246-197507000-00003

[20] Srinivasan, A.K., Shackcloth, M.J., Grayson, A.D. and Fabri, B.M. (2003) Preoperative Beta-Blocker Therapy in Coronary Artery Bypass Surgery: A Propensity Score Analysis of Outcomes. Interactive Cardiovascular and Thoracic Surgery, 2, 495-500. http://dx.doi.org/10.1016/S1569-9293(03)00132-4

[21] Koçoğullari, C.U., Emmiler, M., Ayva, E., Sasirtan, T., Eren, N. and Cekirdekci, A. (2008) Preoperative Prophylaxis Can Decrease Rates of Atrial Fibrillation in Open Heart Surgery: A Retrospective Study. Heart Surgery Forum, 11, E159-E163. http://dx.doi.org/10.1532/HSF98.20081003

[22] Andrews, T.C., Reimold, S.C., Berlin, J.A. and Antman, E.M. (1991) Prevention of Supraventricular Arrhythmias after Coronary Artery Bypass Surgery: A Meta-Analysis of Randomised Control Trials. Circulation, 84, III236-III244.

[23] Grigore, A.M., Armory, D.W. and White, W.D. (1999) $\beta$-Blockade and Neurological Outcome in Cardiac Surgery. Anesthesia Analgesia, 88, 89. 
Scientific Research Publishing (SCIRP) is one of the largest Open Access journal publishers. It is currently publishing more than 200 open access, online, peer-reviewed journals covering a wide range of academic disciplines. SCIRP serves the worldwide academic communities and contributes to the progress and application of science with its publication.

Other selected journals from SCIRP are listed as below. Submit your manuscript to us via either submit@scirp.org or Online Submission Portal.
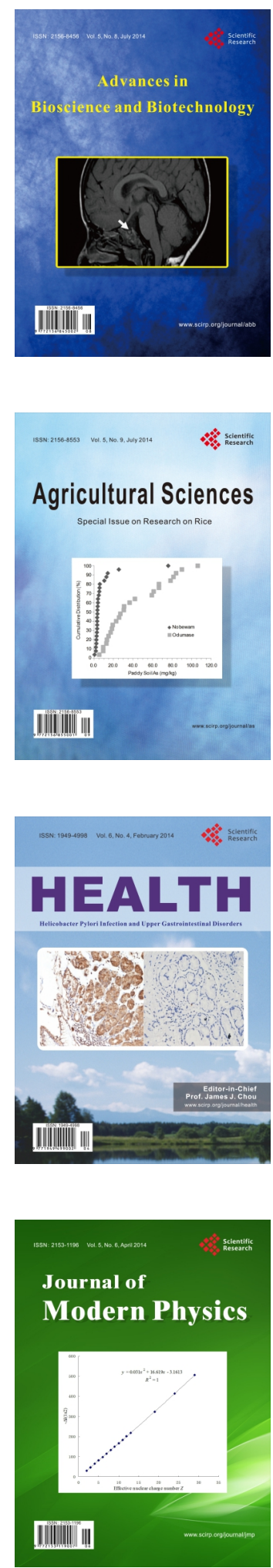
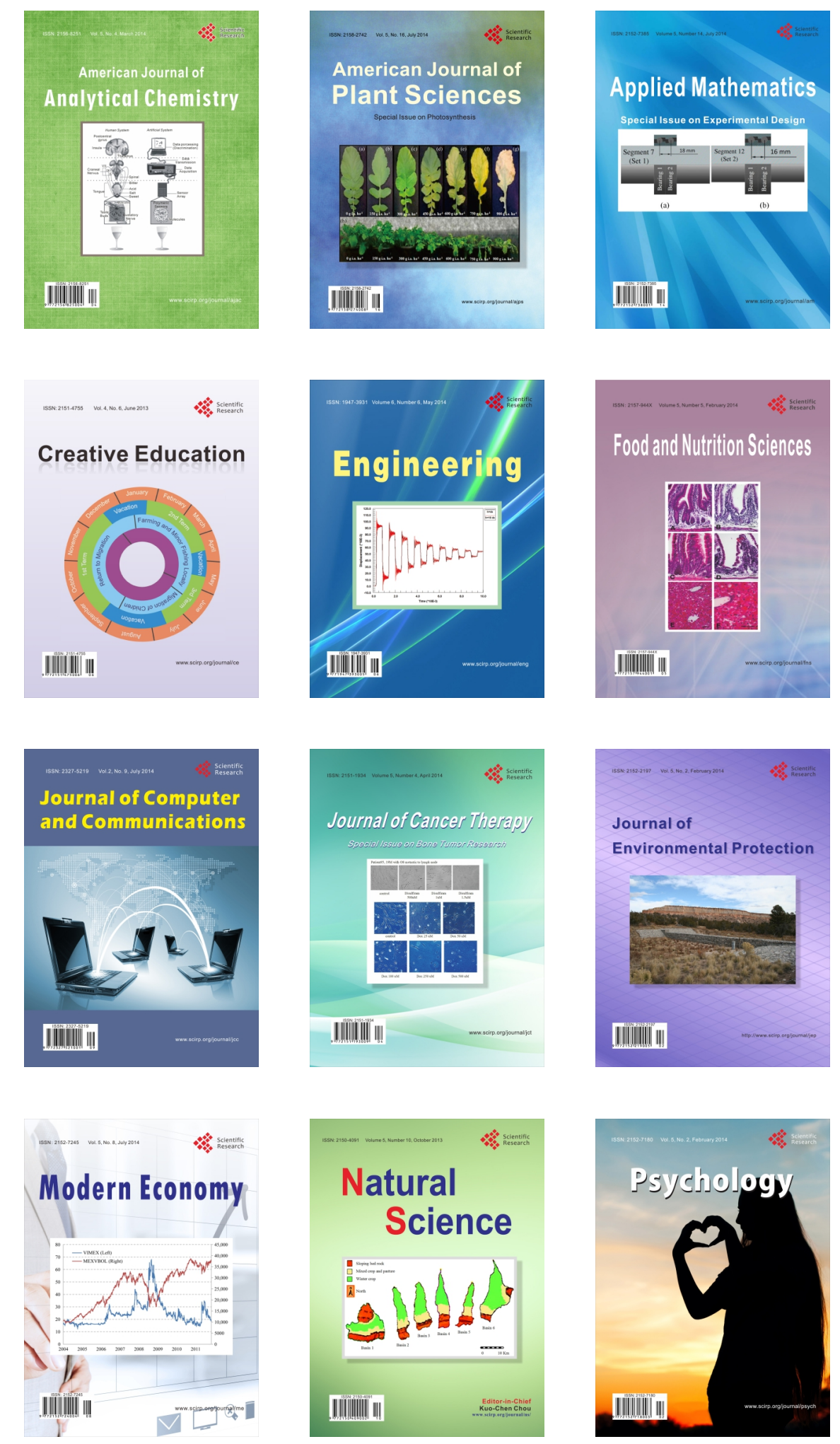